\title{
Prognostic Factors Affecting Visual Recovery in Terson Syndrome with Aneurysmal Subarachnoid Hemorrhage
}

\author{
Mi Sun Choi, MD', Joo Hee Lee, RN', Ji Hun Song, MD, PhD², Yong Cheol Lim, MD' \\ Departments of ${ }^{1}$ Neurosurgery, ${ }^{2}$ Ophthalmology, Ajou University School of Medicine, Suwon, Korea
}

Background: The purpose of this study was to survey the anatomical angiographic finding of the aneurysm and identify parameters associated with visual recovery of the patients with Terson syndrome (TS).

Methods: This retrospective study was conducted on 494 patients with aneurysmal subarachnoid hemorrhage (SAH) from 2008 to 2015. Radiologists independently reviewed findings on computed tomography scans and cerebral digital subtraction angiography. Ophthalmologists conducted ophthalmological examinations for patients who had no communication problem. The degree of visual acuity recovery (DVAR) was measured based on the visual acuity difference between the initial and sixth-month follow-up. Favorable visual recovery was defined as DVAR $>0.4$.

Results: A total of 494 patients diagnosed with aneurysmal SAH were given admission to a single institute, of whom 171 received ophthalmological examinations. Of the total, 40 patients were diagnosed with TS and 54 eyeballs were affected by vitreous or retinal hemorrhage. In the multivariable analysis, male sex (odds ratio [OR] 9.530; 95\% confidence interval [CI] 1.824-49.801), favorable Glasgow coma scale (GCS) ( $\geq 13$ points) (OR 8.073; 95\% Cl 1.226-53.148), and anterior orientation of aneurysm (OR 5.006; 95\% Cl 1.842-29.751) were identified as independent factors predicting favorable visual recovery after adjusting covariables.

Conclusion: TS was identified in 23.4\% of patients with aneurysmal SAH. Male sex, favorable GCS at admission, and anterior orientation of the aneurysm were identified as prognostic factors for favorable visual recovery. It is proposed that positive ophthalmologic consultation and treatment can be helpful in improving vision and quality of life of TS patients.

J Neurocrit Care 2017;10(2):99-106

Key words: Prognosis; Visual acuity; Subarachnoid hemorrhage

\author{
Received October 16, 2017 \\ Revised November 28, 2017 \\ Accepted December 2, 2017 \\ Corresponding Author: \\ Yong Cheol Lim, MD \\ Department of Neurosurgery, Ajou \\ University School of Medicine, 164 \\ World cup-ro, Yeongtong-gu, Suwon \\ 16499, Korea \\ Tel: +82-31-219-5230 \\ Fax: +82-31-219-5238 \\ E-mail: nsyclim@gmail.com \\ Copyright $\odot 2017$ The Korean Neurocritical \\ Care Society
}

\section{INTRODUCTION}

In 1881, the German ophthalmologist, Moritz Litten, first described the incident of vitreous bleeding with subarachnoid hemorrhage (SAH). ${ }^{1}$ Terson syndrome (TS) was first described by the French ophthalmologist, Albert
Terson in 1900, ${ }^{2}$ as vitreous or subhyaloid hemorrhage secondary to intracerebral hemorrhage and the main cause of the syndrome is SAH from a ruptured intracranial aneurysm. ${ }^{3}$ The intraocular hemorrhages of any type (retinal, subhyaloid or vitreous) have been documented in 10-40\% of individuals with $\mathrm{SAH}{ }^{4}$

cc) This is an Open Access article distributed under the terms of the Creative Commons Attribution Non-Commercial License (http://creativecommons.org/licenses/by$\mathrm{nc} / 4.0$ ) which permits unrestricted non-commercial use, distribution, and reproduction in any medium, provided the original work is properly cited. 
The mechanism underlying TS remains as controversial and poorly understood. Currently, it has been proposed that a sudden increase in intracranial pressure passed via the optic nerve sheath to the optic nerve head obstructs the central vein and retinochoroidal anastomosis at the optic nerve head. ${ }^{5}$ The subsequent rising intravascular pressure causes retinal venous stasis, resulting in intraocular hemorrhage. ${ }^{6}$

In this study, we investigated the incidence of intraretinal and vitreous hemorrhage, identified aneurysmal location or orientation based on 4-vessel digital subtraction angiography (DSA) or computed tomographic (CT) angiography and the prognostic parameters associated with visual recovery of patients suffering from SAH.

\section{METHODS}

Demographic data for all patients were obtained from a retrospectively maintained database. The study was conducted after approval from the institutional review board of Ajou University medical center (AJIRB-MED-MDB-17-037). Between September 2008 and April 2015, the patients were admitted to a single institute and diagnosed with a rupture of an intracranial aneurysm. The diagnosis of ruptured aneurysms was established by CT angiography scan and cerebral DSA to demonstrate an underlying aneurysm within 12 hours of the admission. Within seven days after surgical treatment for the aneurysm, the ophthalmologists performed ophthalmological examinations including visual acuity, pupillary reflexes, and fundoscopic appearance after induced mydriasis, except for ruptured arteriovenous malformation and non-aneurysmal SAH or the patients who could not read and speak at the time of vision test. The visual acuity was measured using Yong-Han Jin's distance visual acuity test. The visual acuity difference between the initial and sixth-month follow-up was expressed as the degree of visual acuity recovery (DVAR). Favorable visual recovery was defined as an improvement of three lines or more compared to the initial visual acuity with reference to the reports by Lee and $\mathrm{Kim}^{7}$ and Jeong et al. ${ }^{8}$ The DVAR were divided into unfavorable and favorable recovery groups based on 0.4. TS was classified as retinal, vitreous or mixed retinal to vitreous hemorrhage for this study.

The initial clinical status of patients was evaluated based on Hunt and Hess $(\mathrm{HH})$ grade, Fisher classification and Glasgow coma scale (GCS) score at the time of emergency department admission. The anatomical location and orientation (using CT angiography and cerebral DSA) of the studied aneurysms were recorded by radiologists. The neurosurgeon performed surgical clipping or endovascular coiling within 24 hours of admission.

The factors affecting visual recovery were investigated using the multivariate logistic regression analysis. SPSS version 22.0 (SPSS Inc., Chicago, IL, USA) was used for all statistical analyses. Mann-Whitney test was used to compare visual recovery and variables between the groups, and Fisher's exact test was used to compare categorical variables. Statistical significance was defined when the $P$ was less than 0.05 .

\section{RESULTS}

Totally 494 patients with aneurysmal SAH were admitted in a single institute between September 2008 and April 2015 and ophthalmologists performed ophthalmologic examinations on 171 patients. The mean age of the patients was 44.3 years (range 27-67 years). Three-hundredtwenty-three patients were excluded from ophthalmologic examinations based on high severity and the patients did not want to be examined nor had any symptoms. Patients with insufficient medical records were excluded from enrollment. Of the 171 patients, 40 were diagnosed with TS, and 131 were non-TS. Of the total 40 patients, 24 were men and 16 were women. Analysis of our data revealed no statistically significant difference between men and women $\left(\chi^{2}=0.0439\right.$, $\mathrm{df}=1, P=0.563)$, and anterior orientation of an aneurysm $\left(\chi^{2}=0.0021, \mathrm{df}=1, P=0.872\right)$ with regard to the incidence of TS. The difference in the incidence of TS among patients with admitting GCS score $\geq 13$ points and those with GCS score $<13$ reached statistical significance $\left(\chi^{2}=28.198, \mathrm{df}=1\right.$, 
$P=0.002)$. The incidence of TS was higher among the patients with $\mathrm{HH}$ grade $\left(\chi^{2}=47.052, \mathrm{df}=1, P=0.001\right)$ and Fisher grade ( $\left.\chi^{2}=52.768, \mathrm{df}=1, P=0.001\right)$ more than 2 points (Table 1).

In 40 patients with TS (23\%), 54 eyeballs were affected by vitreous or retinal hemorrhage related to aneurysmal SAH including 38 (70.4\%) with vitreous hemorrhage, 12 (22.2\%) with retinal hemorrhage, and 4 (7.4\%) with mixed vitreous and retinal hemorrhage. Bilateral ocular hemorrhage was identified in 14 (35\%) patients, whereas right and left side eye was affected in 12 (30\%) and 14 (35\%) patients, respectively. In the first CT performed in the emergency department, intraocular hemorrhage was ob-

Table 1. Characteristics of TS and non-TS in 171 patients with aneurysmal SAH

\begin{tabular}{|c|c|c|}
\hline Variable & $\begin{array}{l}\text { No. of TS } \\
(n=40)\end{array}$ & $\begin{array}{l}\text { No. of non-TS } \\
\quad(n=131)\end{array}$ \\
\hline \multicolumn{3}{|l|}{ Sex } \\
\hline Male & $24(60)$ & $77(58.8)$ \\
\hline Female & $16(40)$ & $54(41.2)$ \\
\hline \multicolumn{3}{|l|}{ Fisher grade } \\
\hline$\leq 2$ & $3(7.5)$ & $115(87.8)$ \\
\hline$>2$ & $37(92.5)$ & $16(12.2)$ \\
\hline \multicolumn{3}{|l|}{$\mathrm{HH}$ grade } \\
\hline$\leq 2$ & $6(15)$ & $108(82.4)$ \\
\hline$>2$ & $34(85)$ & $23(17.6)$ \\
\hline \multicolumn{3}{|l|}{ GCS score } \\
\hline$<13$ & $22(55)$ & $14(10.7)$ \\
\hline$\geq 13$ & $18(45)$ & $117(89.3)$ \\
\hline \multicolumn{3}{|l|}{ Location of aneurysm } \\
\hline Anterior circulation* & $33(82.5)$ & $84(64.1)$ \\
\hline Posterior circulation $^{\dagger}$ & $7(17.5)$ & $47(35.9)$ \\
\hline \multicolumn{3}{|l|}{$\begin{array}{l}\text { Orientation of an } \\
\text { aneurysm }\end{array}$} \\
\hline Anterior & $14(35)$ & $62(47.3)$ \\
\hline Others & $26(65)$ & $69(52.7)$ \\
\hline
\end{tabular}

TS, Terson syndrome; SAH, subarachnoid hemorrhage; $\mathrm{HH}$, Hunt and Hess; GCS, Glasgow coma scale.

Values are presented as number (\%).

*Anterior communicating artery, middle cerebral artery, posterior communicating artery, anterior choroidal artery, and internal carotid artery.

${ }^{\dagger}$ Vertebral artery and posterior inferior cerebellar artery. served in 10 patients (25\%) in right side eye, in 11 patients $(27.5 \%)$ in left side eye and in $12(30 \%)$ in bilateral eyes. However, no ocular hemorrhage was observed in 7 patients (17.5\%).

Of the 40 patients, patients with underlying eye disease included one case with cataract, one case with corneal opacity and two cases with intravitreal implantation. Initial ophthalmological evaluation (mean 7 days; range 1-117 days) was performed in thirteen eyes (24.1\%) within seven days. Mean duration of follow-up ophthalmological examination was six months (range 2-36 months). Ophthalmologic interventions were considered according to the ophthalmologist's decision in case of no improvement of bleeding on follow-up examination despite conservative treatment. Twenty-six (48.1\%) of 54 eyes were treated by ophthalmologic interventions like trans pars planar vitrec-

A

\section{Location}

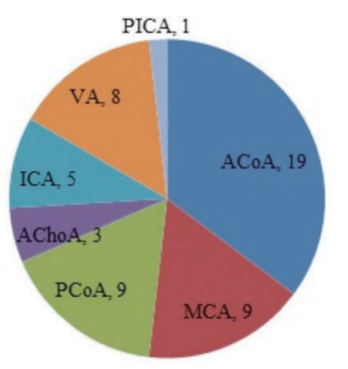

- ACOA

- MCA

$=\mathrm{PCoA}$

- AChoA

$\because$ ICA

$\because \mathrm{VA}$

-PICA

\section{B}

Orientation

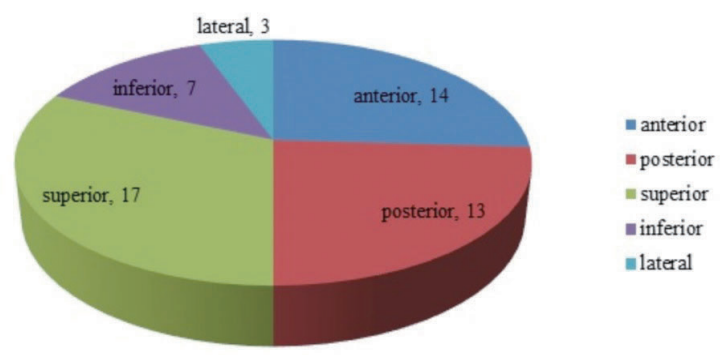

Figure 1. Angiographic finding of an anatomical aneurysm in 54 eyes with Terson syndrome. Distribution of location of the aneurysm (A) and orientation of the aneurysm (B). ACoA, anterior communicating artery; MCA, middle cerebral artery; $\mathrm{PCoA}$, posterior communicating artery; $\mathrm{AChoA}$, anterior choroidal artery; ICA, internal carotid artery; VA, vertebral artery; PICA, posterior inferior cerebellar artery. 
tomy (TPPV), intra-vitreous Avastin (Bevacizumab; Roche, Basel, Switzerland) injection or laser photocoagulation.

Data and statistical values of 54 eyes with respect to sex, age, $\mathrm{HH}$ grade, Fisher grade, GCS score, neurosurgical treatment type, and ophthalmologic intervention were presented,

Table 2. Characteristics and DVAR of 54 eyes with Terson syndrome

\begin{tabular}{|c|c|c|c|}
\hline Variable & No. of eyes & $\begin{array}{l}\text { Mean } \\
\text { DVAR }\end{array}$ & $P$ value \\
\hline Sex & & & $0.001 *$ \\
\hline Male & $31(57.4)$ & 0.53 & \\
\hline Female & $23(42.6)$ & 0.24 & \\
\hline Age & & & 0.175 \\
\hline$\leq 45$ & $24(44.4)$ & 0.48 & \\
\hline$>45$ & $30(55.6)$ & 0.35 & \\
\hline Fisher grade & & & $0.001 *$ \\
\hline$\leq 2$ & $3(5.6)$ & 0.12 & \\
\hline$>2$ & $51(94.4)$ & 0.43 & \\
\hline HH grade & & & 0.557 \\
\hline$\leq 2$ & $9(16.7)$ & 0.34 & \\
\hline$>2$ & $45(83.3)$ & 0.42 & \\
\hline GCS score & & & $0.016^{*}$ \\
\hline$<13$ & $35(64.8)$ & 0.32 & \\
\hline$\geq 13$ & $19(35.2)$ & 0.56 & \\
\hline Aneurysm treatment & & & 0.948 \\
\hline Coil & $35(64.8)$ & 0.40 & \\
\hline Clip & $19(35.2)$ & 0.41 & \\
\hline $\begin{array}{l}\text { Ophthalmological } \\
\text { intervention }\end{array}$ & & & $0.035^{*}$ \\
\hline Not performed & $28(51.9)$ & 0.31 & \\
\hline Performed & $26(48.1)$ & 0.51 & \\
\hline $\begin{array}{l}\text { Intraocular } \\
\text { hemorrhagic type }\end{array}$ & & & $0.01 *$ \\
\hline Vitreous hemorrhage & $38(70.4)$ & 0.49 & \\
\hline Retinal hemorrhage & $12(22.2)$ & 0.25 & \\
\hline Mixed & $4(7.4)$ & 0.05 & \\
\hline $\begin{array}{l}\text { Ophthalmologic } \\
\text { examination onset } \\
\text { (days) }\end{array}$ & & & 0.566 \\
\hline$\leq 7$ & $13(24.1)$ & 0.46 & \\
\hline$>7$ & $41(75.9)$ & 0.39 & \\
\hline
\end{tabular}

DVAR, the degree of visual acuity recovery; $\mathrm{HH}$, Hunt and Hess; GCS, Glasgow coma scale.

Values are presented as number (\%).

$\star P<0.05$. and the location and orientation of an aneurysm were also investigated. The mean DVAR was 0.4 in our study. Statistical analysis revealed significant difference in DVAR in terms of sex (male vs. female; $P=0.001$ ), GCS score ( $<13$ vs. $\geq 13$; $P=0.016$ ), Fisher grade ( $\leq 2$ vs. $>2 ; P=0.001$ ), ophthalmologic intervention (not performed vs. performed; $P=0.035$ ), and type of ophthalmological hemorrhage (vitreous vs. retinal vs. mixed; $P=0.01$ ). There was no statistical correlation regarding onset time of ophthalmological examination ( $\leq 7$ days vs. $>7$ days; $P=0.566$ ) (Table 2 ).

Locations of aneurysm were distributed in 19 cases (35.2\%) with anterior communicating artery (ACoA), 9 cases (16.7\%) with middle cerebral artery (MCA), 9 cases (16.7\%) with posterior communicating artery (PCoA), 5 cases (9.3\%) with internal carotid artery (ICA), and 8 cases $(14.8 \%)$ with vertebral artery. Orientations of the aneurysm were followed as 17 cases (31.5\%) with superior direction, 14 cases (25.9\%) with anterior direction, and 13 cases (24.1\%) with posterior direction (Fig. 1). The location of the aneurysm was divided into anterior and posterior circulation. The anterior circulation included ACoA, MCA, PCoA, anterior choroidal artery, and ICA. The orientation of the aneurysm was divided into anterior and other directions. The incidence for the location of the aneurysm was high in the anterior circulation (83.3\%), but there was no significant difference compared with DVAR of posterior circulation ( $P=0.207$ ). Analysis of orientation of the aneu-

Table 3. Location and orientation of aneurysms in 54 eyes

\begin{tabular}{lccc}
\hline Characteristics & No. of eyes & Mean DVAR & $P$ value \\
\hline $\begin{array}{l}\text { Location of aneurysm } \\
\text { Anterior circulation* }\end{array}$ & $45(83.3)$ & 0.38 & 0.207 \\
$\begin{array}{l}\text { Posterior circulation } \\
\end{array}$ & $9(16.7)$ & 0.54 & \\
$\begin{array}{l}\text { Orientation of the } \\
\text { aneurysm }\end{array}$ & & $0.034^{\ddagger}$ \\
$\quad$ Anterior & $14(25.9)$ & 0.58 & \\
Others & $40(74.1)$ & 0.35 & \\
\hline
\end{tabular}

DVAR, the degree of visual acuity recovery.

*Anterior communicating artery, middle cerebral artery, posterior communicating artery, anterior choroidal artery, and internal carotid artery.

${ }^{\dagger}$ Vertebral artery and posterior inferior cerebellar artery. ${ }^{\ddagger} P<0.05$. 
rysm exhibited a statistically significant difference in DVAR about anterior orientation (anterior orientation vs. other orientation; $P=0.034$ ) (Table 3).

The favorable recovery group with DVAR greater than 0.4 showed statistical significance in sex $(P=0.001), G C S$ score $(P=0.002)$, orientation of aneurysm $(P=0.037)$, and oph- thalmological intervention $(P=0.015)$. But, no statistical significance was observed between the DVAR and factors such as $\mathrm{HH}$ grade $(P=0.804)$, surgical treatment of the aneurysm ( $P=0.465)$, intraocular hemorrhagic type $(P=0.065)$, and location of the aneurysm ( $P=0.461$ ) (Table 4).

Multivariate logistic regression analysis of these pa-

Table 4. Comparison of characteristics between unfavorable and favorable visual recovery group

\begin{tabular}{|c|c|c|c|}
\hline Characteristics & Unfavorable recovery* No. of eyes & Favorable recovery $^{\dagger}$ No. of eyes & $P$ value \\
\hline Mean age & $45.9 \pm 8.4$ & $42.1 \pm 6.9$ & 0.083 \\
\hline Sex (male) & $12(37.5)$ & $19(86.4)$ & $0.001^{\ddagger}$ \\
\hline Fisher grade & & & 0.262 \\
\hline$\leq 2$ & $3(9.4)$ & 0 & \\
\hline$>2$ & $29(90.6)$ & $22(100)$ & \\
\hline $\mathrm{HH}$ grade & & & 0.804 \\
\hline$\leq 2$ & $5(15.6)$ & $4(18.2)$ & \\
\hline$>2$ & $27(84.4)$ & $18(81.8)$ & \\
\hline GCS score & & & $0.002^{\ddagger}$ \\
\hline$<13$ & $26(81.3)$ & $9(40.9)$ & \\
\hline$\geq 13$ & $6(18.8)$ & $13(59.1)$ & \\
\hline Location of aneurysm & & & 0.461 \\
\hline Anterior circulation & $28(87.5)$ & $17(77.3)$ & \\
\hline Posterior circulation & $4(12.5)$ & $5(22.7)$ & \\
\hline Orientation of the aneurysm & & & $0.037^{\ddagger}$ \\
\hline Anterior & $5(15.6)$ & $9(40.9)$ & \\
\hline Others & $27(84.4)$ & $13(59.1)$ & \\
\hline Hydrocephalus & $12(50)$ & $12(50)$ & 0.215 \\
\hline $\mathrm{ICH}$ & $18(69.2)$ & $8(30.8)$ & 0.151 \\
\hline Aneurysm treatment & & & 0.465 \\
\hline Coil & $22(68.8)$ & $13(59.1)$ & \\
\hline Clip & $10(31.3)$ & $9(40.9)$ & \\
\hline $\begin{array}{l}\text { Mean time of ophthalmologic } \\
\text { examination (days) }\end{array}$ & $67.8 \pm 149.9$ & $49.1 \pm 85.4$ & 0.6 \\
\hline Intraocular hemorrhagic type & & & 0.065 \\
\hline Vitreous hemorrhage & $18(56.3)$ & $20(90.9)$ & \\
\hline Retinal hemorrhage & $10(31.3)$ & $2(9.1)$ & \\
\hline Mixed & $4(12.5)$ & 0 & \\
\hline Ophthalmological intervention & & & $0.015^{\ddagger}$ \\
\hline Not performed & $21(65.6)$ & $7(31.8)$ & \\
\hline Performed & $11(34.4)$ & $15(68.2)$ & \\
\hline
\end{tabular}

$\mathrm{HH}$, Hunt and Hess; GCS, Glasgow coma scale; ICH, intracranial hemorrhage.

Values are presented as mean \pm standard deviation or number (\%) unless otherwise indicated.

*DVAR $\leq 0.4$.

${ }^{\dagger}$ DVAR $>0.4$.

${ }^{\ddagger} P<0.05$. 
Table 5. Multivariate logistic regression analysis of factors for influencing favorable recovery (DVAR>0.4)

\begin{tabular}{lcccc}
\hline & Unadjusted OR $(95 \% \mathrm{Cl})$ & $P$ value & Adjusted OR $(95 \% \mathrm{Cl})$ & $P$ value \\
\hline Sex $($ male) & $0.154(0.079-0.232)$ & $0.001^{*}$ & $9.530(1.824-49.801)$ & $0.008^{*}$ \\
GCS score $\geq 13$ & $0.132(0.039-0.215)$ & $0.002^{*}$ & $8.073(1.226-53.148)$ & $0.030^{*}$ \\
Anterior orientation & $0.068(0.002-0.140)$ & $0.037^{*}$ & $5.006(1.842-29.751)$ & $0.017^{*}$ \\
Ophthalmological intervention & $0.329(0.086-0.575)$ & $0.015^{*}$ & $1.567(0.404-6.083)$ & 0.516 \\
\hline
\end{tabular}

DVAR, the degree of visual acuity recovery; OR, odds ratio; $\mathrm{Cl}$, confidence interval; GCS Glasgow coma scale.

$\star P<0.05$.

rameters identified statistical significance for male $(\mathrm{df}=1$, $P=0.008)$, GCS score $(\geq 13)(\mathrm{df}=1, P=0.03)$, and anterior orientation of aneurysm ( $\mathrm{df}=1, P=0.017$ ) (Table 5).

\section{DISCUSSION}

TS has been referred to the occurrence of vitreous hemorrhage in patients with SAH secondary to a ruptured aneurysm however, it has been only rarely described in association with subdural hematomas or traumatic SAH. ${ }^{9-11}$ It is most frequently reported with aneurysm of the anterior circulation, particularly of ACOA and ICA origin. ${ }^{10-13}$ In our report, ACOA (35.2\%) exhibited the highest frequency showing similarity in results with other studies, but it was not statistically significant with respect to the location of the aneurysm (anterior circulation vs. posterior circulation; $P=0.207$ ). Variations have been observed in the incidence of Terson hemorrhage among published studies., ${ }^{3,12,14-16}$ The incidence has been reported to range between 2.6 and 27\% in patients suffering from aneurysmal SAH., ${ }^{6,14,15,17,18}$ In our current study, $23.4 \%$ of our patients developed TS.

The intraocular hemorrhage observed in TS is usually bilateral; however, it can be asymmetrical in nature.12 The first attempt to explain TS suggested that blood crosses the subarachnoid space into its continuation within the optic nerve sheath. It was thought that blood was driven through the sclera in the porous region where the optic nerve enters the globe, and finally appears in the vitreous space within the eyes. ${ }^{19}$

The prognosis of aneurysmal SAH patients with TS has been reported to be poor. Many studies have reported high mortality rate in patients with TS compared to patients without TS. ${ }^{1,12,16}$ However, the outcome of visual recovery in surviving patients with aneurysmal SAH has been reported to be good and most of the vitreous hemorrhage has been reported to be cleared spontaneously within months. ${ }^{11,12,20}$ However, in our study, the statistically significant difference for DVAR was demonstrated in males, higher GCS score, and aneurysm of anterior orientation. There was little information about the visual recovery according to the orientation of an aneurysm in previous research, but we identified that DVAR was excellent in TS patients with aneurysm of anterior orientation compared to others ( $P=0.037$ ). It was considered that ophthalmologic problems were detected at an early stage by ophthalmologic examination in patients with higher GCS, and visual acuity improved through active treatment such as intervention. The orientation of the aneurysm is difficult to explain because there is no known mechanism until date.

In our series, the ophthalmological interventions including TPPV, intra-vitreous Avastin injection or laser photocoagulation were performed in 26 eyes (48.1\%). The patients undergoing ophthalmological intervention showed statistical significance compared to those who did not (not performed vs. performed; $P=0.035$ ), and the DVAR of 0.4 or more was present in the favorable recovery group. Czorlich et al. ${ }^{21}$ reported that early TPPV for vitreous hemorrhage contributed to improve best-corrected visual acuity and support neurological rehabilitation. In our study, DVAR of aneurysmal SAH patients having ophthalmological examination within a week was similar to the DVAR of aneurysmal SAH patients undergoing ophthalmological examination a week later, and there was no statistical correlation ( $P=0.566)$.

The ophthalmologists have difficulty in diagnosing intraocular hemorrhage immediately because there of the 
limitation from mydriasis depending on the patient's neurological condition. Due to the difficulty in evaluating and making prompt diagnosis, TS is underestimated and its diagnosis can be easily missed. Koskela et al. demonstrated that conventional CT scan has high specificity for detecting $\mathrm{TS}^{22}$ In our study, CT scan findings were in accordance with the ophthalmological examination in 24 eyes (44.4\%), not in accordance with the ophthalmological examination in 23 eyes (42.6\%), and cannot detect ocular hemorrhage in 7 eyes (13\%).

This study has several limitations. First, the number of subjects was small. In about $76 \%$ of cases, the visual acuity test was performed late (from the 7 th day to the 117 th day after admission). The late diagnosis of TS did not take into account the risk of hemorrhage such as coagulopathy or taking antiplatelet agents. In future, further study on the mechanism of visual improvement in the anterior orientation of the aneurysm is required.

\section{CONCLUSION}

It was observed that TS occurred in about $23.4 \%$ of patients with aneurysmal SAH in our study. The DVAR was higher in the aneurysm of anterior orientation, although the location of an aneurysm was not related to the DVAR. The type of intraocular hemorrhage has no correlation with visual recovery. Also, analysis of favorable visual recovery exhibited the statistically significant difference in male, higher GCS score, and anterior orientation of an aneurysm. Patients with vitreous hemorrhage among intraocular hemorrhage types had the greatest DVAR. It is proposed that more active ophthalmological evaluation and treatment can be helpful in contributing to rise the quality of life and improving vision.

\section{REFERENCES}

1. Medele RJ, Stummer W, Mueller AJ, Steiger HJ, Reulen HJ. Terson's syndrome in subarachnoid hemorrhage and severe brain injury accompanied by acutely raised intracranial pressure. / Neurosurg 1998;88:851-4.

2. Terson PDA. Hemorrhage in the vitreous body during cerebral hemorrhage. La Clin Ophthalmol 1900;22:309-12.

3. Fountas KN, Kapsalaki EZ, Lee GP, Machinis TG, Grigorian AA, Robinson JS, et al. Terson hemorrhage in patients suffering aneurysmal subarachnoid hemorrhage: predisposing factors and prognostic significance. / Neurosurg 2008;109:439-44.

4. McCarron MO, Alberts MJ, McCarron P. A systematic review of Terson's syndrome: frequency and prognosis after subarachnoid haemorrhage. / Neurol Neurosurg Psychiatry 2004;75:491-3.

5. Ness T, Janknecht P, Berghorn C. Frequency of ocular hemorrhages in patients with subarachnoidal hemorrhage. Graefes Arch Clin Exp Ophthalmol 2005;243:859-62.

6. Manschot WA. Subarachnoid hemorrhage; intraocular symptoms and their pathogenesis. Am I Ophthalmol 1954;38:501-5.

7. Lee HJ, Kim HC. The clinical outcome and prognostic factors of vitrectomy for macular epiretinal membranes. I Korean Ophthalmol Soc 2003;44:857-64.

8. Jeong JH, Chun YS, Kim JC. The effects of a subtenoncapsular injection of bevacizumab for ocular surface disease with corneal neovascularization. / Korean Ophthalmol Soc 2009;50:1475-82

9. Espinasse-Berrod MA, David T, Parent DCH, Mayer JM, Deplus S, Merland J), et al. Terson's syndrome. About of 7 cases. / Fr Ophtalmol 1988;11:43-51.

10. Shaw HE Jr, Landers MB 3rd. Vitreous hemorrhage after intracranial hemorrhage. Am J Ophthalmol 1975;80:207-13.

11. Toosi SH, Malton M. Terson's syndrome--significance of ocular findings. Ann Ophthalmol 1987;19:7-12.

12. Garfinkle AM, Danys IR, Nicolle DA, Colohan AR, Brem S. Terson's syndrome: a reversible cause of blindness following subarachnoid hemorrhage. / Neurosurg 1992;76:766-71.

13. Vanderlinden RG, Chisholm LD. Vitreous hemorrhages and sudden increased intracranial pressure. / Neurosurg 1974;41:167-76.

14. Frizzell RT, Kuhn F, Morris R, Quinn C, Fisher WS 3rd. Screening for ocular hemorrhages in patients with ruptured cerebral aneurysms: a prospective study of 99 patients. Neurosurgery 1997:41:529-33; discussion 533-4.

15. Kuhn F, Morris R, Witherspoon CD, Mester V. Terson syndrome. Results of vitrectomy and the significance of vitreous hemorrhage in patients with subarachnoid hemorrhage. 
Ophthalmology 1998;105:472-7.

16. Pfausler B, Belcl R, Metzler R, Mohsenipour I, Schmutzhard E. Terson's syndrome in spontaneous subarachnoid hemorrhage: a prospective study in 60 consecutive patients. / Neurosurg 1996;85:392-4.

17. Roux FX, Panthier JN, Tanghe YM, Gallina P, Oswald AM, Mérienne L, et al. Terson's syndrome and intraocular complications in meningeal hemorrhages (26 cases). Neurochirurgie 1991;37:106-10.

18. Tsementzis SA, Williams A. Ophthalmological signs and prognosis in patients with a subarachnoid haemorrhage. Neurochirurgia (Stuttg) 1984;27:133-5.

19. Doubler FH. A case of hemorrhage into the optic nerve sheath as a direct extension from a diffuse intra-meningeal hemor- rhage caused by rupture of an aneurysm of a cerebral artery. Arch Ophthalmol 1917:46:533-6.

20. Shaw HE Jr, Landers MB, Sydnor CF. The significance of intraocular hemorrhages due to subarachnoid hemorrhage. Ann Ophthalmol 1977;9:1403-5.

21. Czorlich P, Skevas C, Knospe V, Vettorazzi E, Richard G, Wagenfeld $L$, et al. Terson syndrome in subarachnoid hemorrhage, intracerebral hemorrhage, and traumatic brain injury. Neurosurg Rev 2015;38:129-36; discussion 136.

22. Koskela E, Pekkola J, Kivisaari R, Kivelä T, Hernesniemi J, Setälä K, et al. Comparison of CT and clinical findings of Terson's syndrome in 121 patients: a 1-year prospective study. I Neurosurg 2014;120:1172-8. 